Review Article

\title{
The Effects of Salvia miltiorrhiza on Reproduction and Metabolism in Women with Polycystic Ovary Syndrome: A Systematic Review and Meta-Analysis
}

\author{
Wenjuan Shen $\mathbb{D}^{1},{ }^{1}$ Bao Jin $\mathbb{D}^{D},{ }^{2}$ Yaguang Han $\mathbb{D}^{1},{ }^{1}$ Hongwei Wang, ${ }^{2}$ Huan Jiang, ${ }^{2}$ Linlin Zhu, ${ }^{2}$ \\ Mei Han, Jiao Zhang $\left({ }^{3},{ }^{4}\right.$ and Yang Zhang $\mathbb{1}^{5}$ \\ ${ }^{1}$ Department of Obstetrics and Gynecology, First Affiliated Hospital, Heilongjiang University of Chinese Medicine, \\ Harbin 150040, China \\ ${ }^{2}$ Department of Obstetrics and Gynecology, Heilongjiang University of Chinese Medicine, Harbin 150040, China \\ ${ }^{3}$ Centre for Evidence-Based Chinese Medicine, Beijing University of Traditional Chinese Medicine, Beijing 100029, China \\ ${ }^{4}$ Department of National Physician Hall, Second Affiliated Hospital, Heilongjiang University of Chinese Medicine, \\ Harbin 150009, China \\ ${ }^{5}$ Department of Internal Medicine, First Affiliated Hospital, Heilongjiang University of Chinese Medicine, Harbin 150040, China
}

Correspondence should be addressed to Jiao Zhang; 125075956@qq.com and Yang Zhang; yangzhang83@163.com

Received 23 March 2021; Accepted 4 May 2021; Published 17 May 2021

Academic Editor: Yong Wang

Copyright (c) 2021 Wenjuan Shen et al. This is an open access article distributed under the Creative Commons Attribution License, which permits unrestricted use, distribution, and reproduction in any medium, provided the original work is properly cited.

Objective. Polycystic ovary syndrome (PCOS) is the most common endocrine disorder in women of reproductive age. As a traditional medicine, Salvia miltiorrhiza (S. miltiorrhiza) has been widely used in the treatment of many gynecological diseases, but the efficacy of S. miltiorrhiza in women with PCOS has not been assessed. The purpose of this systematic review and metaanalysis was to evaluate the effectiveness and safety of $S$. miltiorrhiza in women with PCOS. Methods. We conducted searches in PubMed, Embase, the Cochrane Library, the China National Knowledge Infrastructure, the Wanfang Database, the Chinese Scientific Journal Database, and the Chinese BioMedical database from inception to December 23, 2020, to identify studies that met the inclusion criteria. The quality of the evidence was estimated using the Cochrane Reviewer Handbook 5.0.0, and the metaanalysis was performed using RevMan 5.3.5 software. Results. Six randomized controlled trials (RCTs) involving 390 patients with PCOS were included. The studies suggested that $S$. miltiorrhiza extract combined with letrozole (LET) was more effective in improving pregnancy rate (RR: $2.60,95 \% \mathrm{CI}: 1.06$ to $6.39, P=0.04$ ) compared to LET alone. S. miltiorrhiza extract was associated with decreased fasting blood glucose (MD: $-0.25,95 \% \mathrm{CI}:-0.37$ to $-0.13, P<0.0001$ ), fasting insulin (MD: $-1.16,95 \% \mathrm{CI}:-1.74$ to $-0.58, P<0.0001$ ), total cholesterol (TC) (MD: $-0.58,95 \%$ CI: -0.72 to $-0.43, P<0.00001$ ), and triglycerides (TG) (MD: -0.31 , 95\% CI: -0.35 to $-0.26, P<0.00001)$ compared with placebo, but not with improvements in body mass index or waist-to-hip ratio (MD: $-1.41,95 \%$ CI: -4.81 to $2.00, P=0.42$; MD: -0.02 , 95\% CI: -0.05 to $0.01, P=0.16$, respectively). There was a significant difference between $S$. miltiorrhiza extract combined with cyproterone acetate (CPA) and CPA alone in terms of decreasing TC (MD: $-0.77,95 \%$ CI: -0.89 to $-0.65, P<0.00001)$, TG (MD: $-0.43,95 \%$ CI: -0.65 to $-0.20, P<0.0001$ ), and low-density lipoprotein cholesterol (MD: $-0.49,95 \%$ CI: -0.66 to $-0.33, P<0.00001)$ and increasing high-density lipoprotein cholesterol (MD: $0.30,95 \%$ CI: $0.20,0.40, P<0.00001)$. In addition, $S$. miltiorrhiza extract also decreased testosterone, follicle-stimulating hormone, and luteinizing hormone. The studies did not mention any adverse events with $S$. miltiorrhiza extract. Conclusion. The current studies indicate that $S$. miltiorrhiza has beneficial effects on reproduction and glucose and lipid metabolism in patients with PCOS, and it is generally safe for clinical application. However, more prospective RCTs with large samples, multiple centers, and longer intervention duration are needed in the future to obtain more reliable conclusions. 


\section{Introduction}

Polycystic ovary syndrome (PCOS) is a heterogeneous endocrine disorder with a prevalence ranging from $6 \%$ to $21 \%$ in adolescent and reproductive age women depending on the diagnostic criteria that are used $[1,2]$. Hyperandrogenemia and metabolic abnormalities are closely related to the occurrence and development of PCOS [3]. Excessive androgens can cause premature follicular atresia, and this results in ovulatory dysfunction and stimulates vigorous sebaceous gland metabolism, subsequently leading to infertility, menstrual disturbances, acne, hirsutism, and other clinical symptoms. More than $60 \%$ of PCOS patients will be accompanied by obesity, which can lead to dyslipidemia, abnormal secretion of adipokines, and abnormal steroid metabolism, and obesity further aggravates the occurrence and development of PCOS and increases the risk for type 2 diabetes, hyperinsulinemia, hyperlipidemia, and cardiovascular diseases $[4,5]$. Studies have shown that PCOS patients are mainly concerned with reproductive disorders in the early stages of the disease but then become more concerned with the metabolic abnormalities in the later stages [6]. PCOS seriously affects the quality of life of patients and imposes a heavy burden on their families and society as a whole. A Bayesian modelling study in the UK in 2018 showed that women with PCOS require at least $£ 237$ million in treatment costs every year [7]. Thus, it is important to develop methods to improve the fertility of PCOS patients, reduce androgen levels, and correct metabolic disorders, and find ways to delay the development of the disease.

At present, western medicine (WM) treatments for PCOS mainly include ovulation-inducing drugs, especially combination oral contraceptives and insulin-sensitization agents, which act on different mechanisms to improve the pathological manifestations of PCOS, but these drugs cause abnormal uterine bleeding, weight gain, gastrointestinal discomfort, liver damage, and other side effects [8]. Thus, many PCOS patients seek complementary and alternative medicine treatments to enhance the efficacy of their treatments and to improve their health. Recent studies have shown that nutritional supplements and herbal medicines as complementary and alternative medicines may help improve the health status of women with PCOS [9], and there is a growing body of evidence that puerarin, semen cuscutae flavonoids, berberine, glycyrrhetinic acid, tanshinone, and other Chinese herbal extracts have advantages in the treatment of this disease [10]. Salvia miltiorrhiza (S. miltiorrhiza), also known as danshen in traditional Chinese medicine, is used for the treatment of cardiovascular and cerebrovascular diseases $[11,12]$. The active components of S. miltiorrhiza are divided into two groups: water-soluble phenolics [13] and lipophilic tanshinones [14]. Tanshinones (including tanshinone I, tanshinone IIA, tanshinone IIB, cryptotanshinone, and dihydrotanshinone I) exhibit diverse biological activities such as androgen reduction [15] and improvement in glucose and lipid metabolism [16, 17], and they have antitumor [18], cardioprotective [19], and neuroprotective [20] effects. Especially in the last decade, several clinical trials have evaluated the efficacy of S. miltiorrhiza for treating PCOS. Cryptotanshinone has been shown to reverse androgen excess and ovarian insulin resistance (IR) in mice by activating the insulin signaling pathway via PI3K and regulating glucose transporter and hormone synthase activity [21]. In addition, Yang et al. [22] demonstrated that cryptotanshinone can effectively reduce serum luteinizing hormone (LH) levels, the LH/follicle-stimulating hormone $(\mathrm{FSH})$ ratio, and testosterone $(\mathrm{T})$ levels, thereby reducing the expression of HMGB1, TLR4, and $\mathrm{NF} \kappa \mathrm{B} / \mathrm{p} 65$ in ovarian tissue and granulosa cells and improving the symptoms of PCOS.

Several randomized clinical trials (RCTs) have investigated the efficacy of $S$. miltiorrhiza in improving the pregnancy rate, fasting blood glucose, fasting insulin, body mass index (BMI), and T levels in patients with PCOS, but the results have been contradictory. Some reports indicated that the clinical pregnancy rate of PCOS patients is significantly increased after tanshinone capsule treatment [23]. However, Wang et al. [24] reported that the tanshinone capsule had no obvious effect on improving the pregnancy rate. In addition, other studies have shown that oral administration of tanshinone capsules in PCOS patients can reduce the fasting blood glucose level [13]. In contrast, Su et al. [25] did not show any effect of tanshinone capsule on fasting blood glucose levels in PCOS patients.

Due to the enthusiasm of PCOS patients for herbal therapy but the lack of strong evidence, evaluating herbal therapy is considered an appropriate research strategy because it may provide relevant answers to the questions of PCOS patients and clinicians. However, RCTs have shown contradictory reproductive and metabolic effects of S. miltiorrhiza in patients with PCOS. Moreover, the results of these RCTs may not be sufficient to draw firm conclusions in this regard. Therefore, in order to evaluate the effects of S. miltiorrhiza on the reproductive and metabolic outcomes of patients with PCOS more comprehensively and scientifically, we conducted a systematic review of the available RCTs in order to provide evidence-based medical guidelines for clinical practice.

\section{Materials and Methods}

This review was carried out according to the Cochrane recommendations and was reported according to the Preferred Reporting Items for Systematic Reviews and MetaAnalyses (PRISMA) statement [26].

2.1. Search Methods. Published articles were searched for in PubMed, Embase, the Cochrane Library, the China National Knowledge Infrastructure (CNKI), the Wanfang Database, the Chinese Scientific Journal Database (VIP), and the Chinese BioMedical database (CBM). The retrieval time was from the establishment of each database to December 23, 2020 , and there were no restrictions on the languages nor publication status. Keywords in the literature retrieval included "Salvia miltiorrhiza," "tanshinone," "cryptotanshinone," "tanshinone capsule," "danshen," "polycystic 
ovary syndrome," "polycystic ovarian syndrome," "PCOS," "polycystic ovary changes," and related synonyms.

2.2. Study Selection. All trials included in our study met the following criteria. (1) Participants were women diagnosed with polycystic ovary syndrome according to the Rotterdam criteria [27] or the recommendation of the American Androgen Excess Society [28]. There was no limitation on nationality, race, physical characteristics, or course of the disease. (2) We accepted RCTs regardless of blinding procedures but only included parallel design studies. (3) The interventions included $S$. miltiorrhiza extract or S. miltiorrhiza extract combined with WM (unlimited dosage form, dose, or duration). (4) The control group should be placebo, WM, or placebo combined with WM. (5) The study included the following outcome indicators: reproductive indicators (pregnancy rate); glucose and lipid metabolism indicators (fasting blood glucose, fasting insulin, total cholesterol (TC), triglycerides (TG), low-density lipoprotein cholesterol (LDL-C), and high-density lipoprotein cholesterol (HDL-C)); clinical symptoms (BMI, waistto-hip ratio (WHR)); reproductive hormones $(\mathrm{T}, \mathrm{LH}$, and FSH); safety and adverse events data.

The exclusion criteria were as follows: (1) repeated publications or articles with unavailable data were excluded; (2) the article was an animal experiment, review, or case report; (3) other traditional Chinese medicine treatments such as acupuncture and massage were used; (4) trials were not RCTs or there were no criteria for how the trial was conducted.;(5) the full text could not be found.

2.3. Literature Screening and Data Extraction. The preliminary articles were imported into NoteExpressV3.3.0 for management. According to the inclusion and exclusion criteria, the titles and abstracts of the articles were read for preliminary screening after eliminating duplicated articles. The full text was then read during rescreening to identify the included articles. Data of each study were collected, including the following: study characteristics (primary author, publication year, study location, study design, and sample size), participant characteristics (mean age), intervention and comparison data (dose and treatment duration), and outcome measures. The results were extracted independently by two authors and then checked for consensus.

2.4. Quality Assessment. The methodological quality of the included RCTs was assessed for risk of bias in accordance with the RCT quality assessment criteria reported in the Cochrane Reviewer Handbook 5.0.0 [29] that focuses on the following six aspects: random sequence generation, assignment concealment implementation, blinding, data integrity, selective reporting with or without results, and other sources of bias, including whether there are clear inclusion/exclusion criteria, whether baseline data are comparable, and whether there is a conflict of interest. For each item, if satisfied, it means there is a "low risk of bias," while contradicted items mean "high risk of bias." When there is not enough information reported in the literature to allow one to make a clear judgment about an item, the item is classified as unclear, implying a moderate risk. The risk of bias for each qualifying study was independently assessed by two reviewers. If there was a disagreement, it was resolved through discussion or with the assistance of a third experienced researcher.

2.5. Data Analysis. RevMan 5.3 .5 by the Cochrane Collaboration Network was used for meta-analysis. Binary variables are presented as the risk ratio (RR) with 95\% confidence interval (CI), and continuous variables are expressed as the mean difference (MD) or standardized mean difference (SMD) with 95\% CI. Heterogeneity was tested by the Q-test, in which $I^{2}$ was used to quantitatively estimate the magnitude of heterogeneity. When $I^{2} \leq 50 \%$ and $P \geq 0.10$, the fixed-effect model was used. If not, a randomeffect model was used. If the heterogeneity was too large, the source of heterogeneity was identified and subgroup analysis or sensitivity analysis was conducted to determine the stability of the results of the meta-analysis.

\section{Results}

3.1. Literature Search Result. The initial search yielded 299 articles that met the search criteria, of which $115,83,17,6$, 49, 24, and 5 articles were from the CNKI, Wanfang, VIP, PubMed, CBM, Embase, and Cochrane Library, respectively. After removing duplicates, 199 articles remained. After scanning the titles and abstracts, we discarded 169 animal studies, evaluations, reviews, and clearly unqualified studies, leaving a total of 30 references for full-text review. After assessment according to the inclusion and exclusion criteria, 24 articles were further excluded, and 6 RCTs [23, 30-34] were included for analysis. The literature selection process is shown in Figure 1.

3.2. Features of the Included Literature. The six RCTs were published between 2015 and 2020 and had sample sizes ranging from 48 to 86 , and the total number of involved patients was 390, including 195 in the intervention groups and 195 in the control groups. Two studies [32, 33] compared the efficacy of $S$. miltiorrhiza extract with placebo, and four studies [23, 30,31,34] compared the efficacy of S. miltiorrhiza extract in combination with WM versus WM alone. The characteristics of all the studies included in the meta-analysis are shown in Table 1.

3.3. Study Quality Assessment. Figure 2 summarizes the risk of bias of the six included RCTs. Four of the trials reported the random sequence generation methods, while the remaining two studies only mentioned "randomization" without describing specific randomization methods. Apart from Leila et al. 2020, the allocation concealment of the studies was not clearly defined. One study reported sample size estimates, and one study reported subjects falling off or being lost to follow-up. All studies were assessed as "low risk" for "selective reporting" because they reported the 


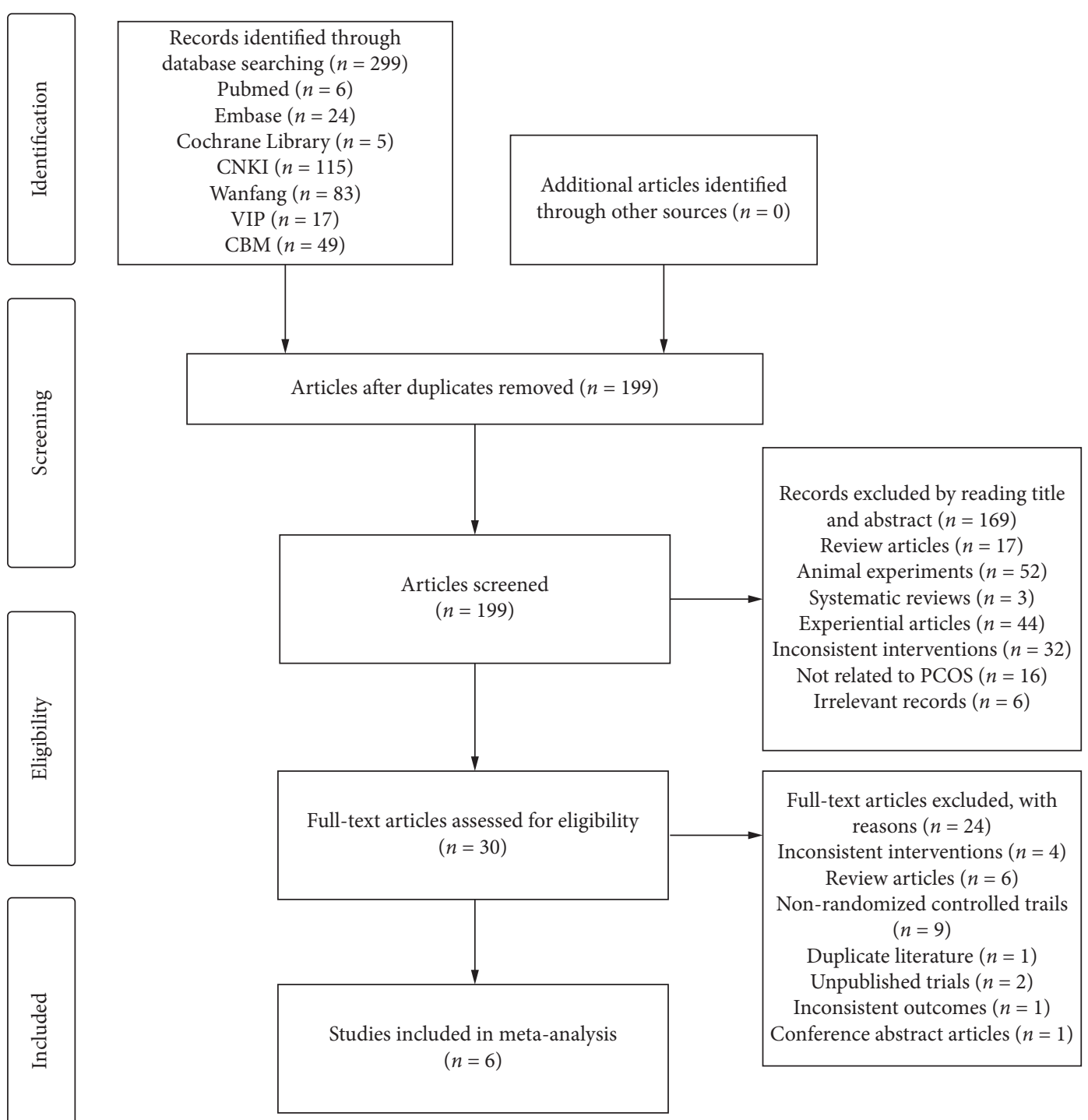

FIgURE 1: Flow diagram of the study selection process.

TABLE 1: The details of the included studies.

\begin{tabular}{|c|c|c|c|c|c|c|c|c|c|}
\hline $\begin{array}{l}\text { Authors/ } \\
\text { published } \\
\text { year }\end{array}$ & Study location & $\begin{array}{l}\text { Study } \\
\text { design }\end{array}$ & $\begin{array}{c}\text { Sample } \\
\text { size }(T / C)\end{array}$ & $\begin{array}{c}\text { Mean age } \\
(\mathrm{T} / \mathrm{C})\end{array}$ & Intervention & Comparison & Dosage & $\begin{array}{l}\text { Duration } \\
\text { of } \\
\text { treatment }\end{array}$ & Outcomes \\
\hline $\begin{array}{l}\text { Zhang } \\
\text { et al. } \\
2015 \text { [33] }\end{array}$ & $\begin{array}{c}\text { Jiangsu } \\
\text { Province, } \\
\text { China }\end{array}$ & RCT & $24 / 24$ & $21-34 / 20-31$ & $\begin{array}{l}\text { S. miltiorrhiza } \\
\text { extract }\end{array}$ & Placebo & $100 \mathrm{mg}$, tid & 3 months & $\begin{array}{c}\text { BMI, WHR, } \\
\text { fasting } \\
\text { blood } \\
\text { glucose, } \\
\text { fasting } \\
\text { insulin, TC, } \\
\text { TG, HDL- } \\
\text { C, LDL-C, } \\
\text { T }\end{array}$ \\
\hline $\begin{array}{l}\text { Amini } \\
\text { et al. } \\
2020 \text { [32] }\end{array}$ & Tehran, Iran & $\mathrm{RCT}$ & $30 / 30$ & $\begin{array}{c}28.07 \pm 4.18 / \\
29.23 \pm 5.44\end{array}$ & $\begin{array}{l}\text { S. miltiorrhiza } \\
\text { extract }\end{array}$ & Placebo & $330 \mathrm{mg}$, qd & 8 weeks & $\begin{array}{l}\text { BMI, WHR, } \\
\text { fasting } \\
\text { blood } \\
\text { glucose, } \\
\text { fasting } \\
\text { insulin }\end{array}$ \\
\hline
\end{tabular}


TABLE 1: Continued.

\begin{tabular}{|c|c|c|c|c|c|c|c|c|c|}
\hline $\begin{array}{l}\text { Authors/ } \\
\text { published } \\
\text { year }\end{array}$ & Study location & $\begin{array}{l}\text { Study } \\
\text { design }\end{array}$ & $\begin{array}{c}\text { Sample } \\
\text { size }(T / C)\end{array}$ & $\begin{array}{l}\text { Mean age } \\
(\mathrm{T} / \mathrm{C})\end{array}$ & Intervention & Comparison & Dosage & $\begin{array}{l}\text { Duration } \\
\quad \text { of } \\
\text { treatment }\end{array}$ & Outcomes \\
\hline $\begin{array}{l}\text { Wu et al. } \\
2016 \text { [30] }\end{array}$ & $\begin{array}{c}\text { Xinjiang } \\
\text { Uygur } \\
\text { Autonomous } \\
\text { Region, China }\end{array}$ & RCT & $36 / 36$ & $28.2 \pm 4.5$ & $\begin{array}{l}\text { S. miltiorrhiza } \\
\text { extract + CPA }\end{array}$ & $\mathrm{CPA}$ & $\begin{array}{l}\text { S. miltiorrhiza } \\
\text { extract } 100 \mathrm{mg} \text {, } \\
\text { tid } \\
\text { CPA } 1 \text { pill, qd }\end{array}$ & 3 months & $\begin{array}{l}\text { TC, TG, } \\
\text { HDL-C, } \\
\text { LDL-C, LH }\end{array}$ \\
\hline $\begin{array}{l}\mathrm{Li} \\
2019[31]\end{array}$ & $\begin{array}{l}\text { Henan } \\
\text { Province, } \\
\text { China }\end{array}$ & RCT & $43 / 43$ & $\begin{array}{c}29.87 \pm 4.23 / \\
30.02 \pm 4.51\end{array}$ & $\begin{array}{l}\text { S. miltiorrhiza } \\
\text { extract + CPA }\end{array}$ & $\mathrm{CPA}$ & $\begin{array}{l}\text { S. miltiorrhiza } \\
\text { extract } 100 \mathrm{mg} \text {, } \\
\text { tid } \\
\text { CPA } 1 \text { pill, qd }\end{array}$ & 3 months & $\begin{array}{l}\text { TC, TG, } \\
\text { HDL-C, } \\
\text { LDL-C, T, } \\
\text { LH, FSH }\end{array}$ \\
\hline $\begin{array}{l}\text { Shi et al. } \\
2016[34]\end{array}$ & $\begin{array}{l}\text { Sichuan } \\
\text { Province, } \\
\text { China }\end{array}$ & RCT & $32 / 32$ & $\begin{array}{c}25.1 \pm 3.8 / \\
25.0 \pm 4.1\end{array}$ & $\begin{array}{l}\text { S. miltiorrhiza } \\
\text { extract + CPA }\end{array}$ & CPA & $\begin{array}{l}\text { S. miltiorrhiza } \\
\text { extract } 100 \mathrm{mg} \text {, } \\
\text { tid } \\
\text { CPA } 1 \text { pill, qd }\end{array}$ & 2 months & $\begin{array}{l}\text { Pregnancy } \\
\text { rate, TC, } \\
\text { TG, HDL- } \\
\text { C, LDL-C }\end{array}$ \\
\hline $\begin{array}{l}\text { Wang } \\
\text { et al. } \\
2016[23]\end{array}$ & $\begin{array}{l}\text { Jiangsu } \\
\text { Province, } \\
\text { China }\end{array}$ & RCT & $30 / 30$ & $\begin{array}{l}18-37 / \\
20-38\end{array}$ & $\begin{array}{l}\text { S. miltiorrhiza } \\
\text { extract + LET }\end{array}$ & Placebo + LET & $\begin{array}{c}\text { S. miltiorrhiza } \\
\text { extract } 100 \mathrm{mg} \text {, } \\
\text { tid } \\
\text { LET NR }\end{array}$ & 3 months & $\begin{array}{l}\text { Pregnancy } \\
\text { rate, BMI, } \\
\text { fasting } \\
\text { blood } \\
\text { glucose, } \\
\text { TC, TG, T, } \\
\text { LH, FSH }\end{array}$ \\
\hline
\end{tabular}

CPA: cyproterone acetate; LET: letrozole; BMI: body mass index; WHR: waist-to-hip ratio; TC: total cholesterol; T: testosterone; TG: triglycerides; FSH: follicle-stimulating hormone; LH: luteotropic hormone; HDL-C: high-density lipoprotein cholesterol; LDL-C: low-density lipoprotein cholesterol; NR: not reported.

prespecified outcomes in the methods. Overall, the quality of six studies is low or remains unclear due to the high proportion of the unclear risk of biases in most studies.

3.4. Effects of S. miltiorrhiza on Pregnancy Rate. Two studies $[23,34]$ compared pregnancy rates and found no significant difference between the combination of $S$. miltiorrhiza extract + CPA versus CPA alone in improving the pregnancy rate $[\mathrm{RR}=1.36,95 \% \mathrm{CI}(0.83,2.21), P=0.22]$. However, the combination of $S$. miltiorrhiza extract + letrozole (LET) was superior to LET alone in improving the pregnancy rate $[\mathrm{RR}=2.60,95 \%$ CI $(1.06,6.39), P=0.04]$.

3.5. Effects of S. miltiorrhiza on Reproductive Hormones. S. miltiorrhiza extract showed a significant reduction of $\mathrm{T}$ [SMD $=-3.31,95 \%$ CI $(-3.90,-2.72), P<0.00001], \mathrm{LH}$ $[\mathrm{MD}=-6.40,95 \% \mathrm{CI}(-8.32,-4.48), P<0.00001]$, and FSH $[\mathrm{MD}=-5.70,95 \% \mathrm{CI}(-6.18,-5.22), P<0.00001]$ versus the placebo group. Moreover, the combination of S. miltiorrhiza extract + CPA significantly decreased T $[\mathrm{SMD}=-4.13,95 \%$ CI $(-4.89,-3.37), P<0.00001]$ and FSH $[\mathrm{MD}=-0.97,95 \%$ CI $(-1.59,-0.35, P=0.002]$, while LH was slightly decreased, but not significantly $[\mathrm{MD}=-2.84,95 \%$ CI $(-5.77,0.08)$, $P=0.06]$, in comparison to the CPA group (Figure 3 ).

3.6. Effects of S. miltiorrhiza on Glucose Metabolism. Compared with the placebo group, PCOS patients treated with $S$. miltiorrhiza extract had significantly lower fasting blood glucose $[\mathrm{MD}=-0.25,95 \%$ CI $(-0.37,-0.13)$, $P<0.0001]$ and fasting insulin $[\mathrm{MD}=-1.16,95 \% \mathrm{CI}(-1.74$, $-0.58), P<0.0001$ ] (Figure 4 ).
3.7. Effects of S. miltiorrhiza on Lipid Metabolism. Two RCTs $[23,33]$ in the analysis compared the effect of S. miltiorrhiza extract and placebo on lipid metabolism in PCOS patients. As shown in Figure 5, the S. miltiorrhiza extract group was more effective in reducing TC $[\mathrm{MD}=-0.58,95 \% \mathrm{CI}(-0.72,-0.43)$, $P<0.00001]$, TG $[\mathrm{MD}=-0.31,95 \%$ CI $(-0.35,-0.26)$, $P<0.00001]$, and LDL-C [MD $=-0.80,95 \% \mathrm{CI}(-0.97,-0.63)$, $P<0.00001]$ and increasing HDL-C $[\mathrm{MD}=0.23,95 \% \mathrm{CI}$ $(0.18,0.28), P<0.00001]$. Our meta-analysis showed that the combination of $S$. miltiorrhiza extract + CPA significantly decreased TC $[\mathrm{MD}=-0.77,95 \%$ CI $(-0.89,-0.65)$, $P<0.00001]$, TG $[\mathrm{MD}=-0.43,95 \%$ CI $(-0.65,-0.20)$, $P<0.0001]$, and LDL-C $[\mathrm{MD}=-0.49,95 \% \mathrm{CI}(-0.66,-0.33)$, $P<0.00001]$ and increased HDL-C [MD $=0.30,95 \%$ CI $(0.20$, 0.40), $P<0.00001]$ compared with $\mathrm{CPA}$ alone (Figure 5).

3.8. Effects of S. miltiorrhiza on Clinical Symptoms. As shown in Figure 6(a), the three RCTs combined did not show any significant change in BMI in PCOS patients after treatment with $S$. miltiorrhiza extract versus placebo $[\mathrm{MD}=-1.41,95 \%$ CI $(-4.81,2.00), P=0.42]$. In addition, there was no evidence that $S$. miltiorrhiza extract was associated with improved WHR compared to placebo $[\mathrm{MD}=-0.02,95 \% \mathrm{CI}$ $(-0.05,0.01), P=0.16$ ] (Figure 6(b)).

3.9. Safety Outcomes. Only the study by Zhang et al. reported no adverse events, and the other studies did not report any information about adverse events.

3.10. Sensitivity Analysis. Sensitivity analysis revealed that excluding individual studies did not remarkably influence the overall effect size of TC, TG, LDL-C, and HDL-C. In 


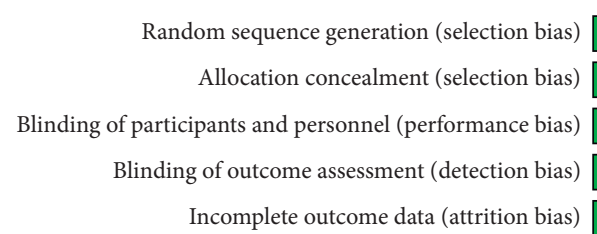

Selective reporting (reporting bias)

Other bias
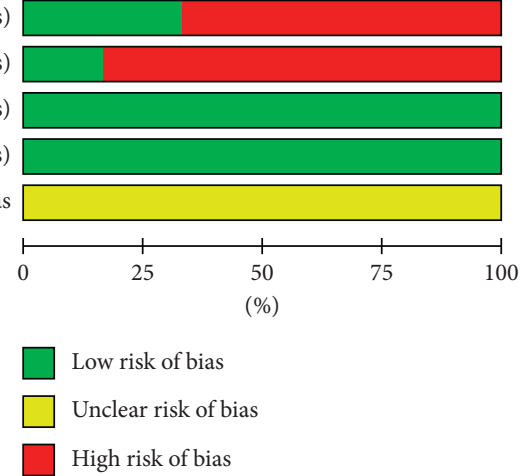

(\%)
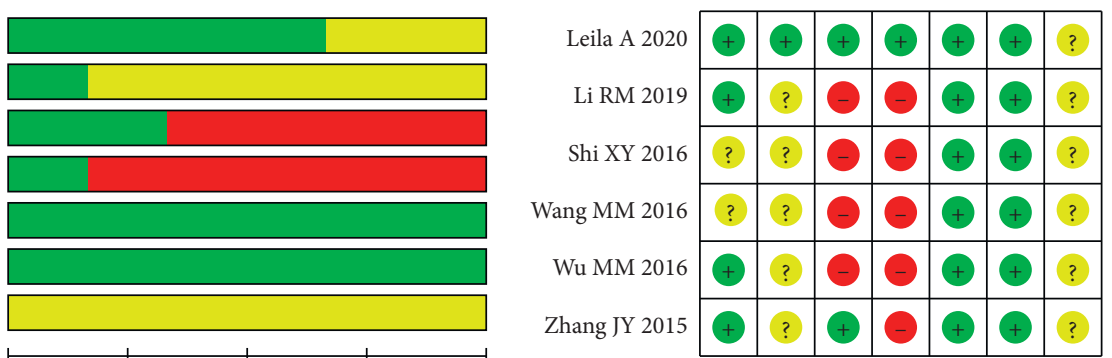

FIGURE 2: The risk of bias for the included studies.

addition, removing $\mathrm{Wu}$ et al. [30], which reported on the effect of Salvia miltiorrhiza extract on lipid metabolism, resulted in a decrease in heterogeneity, whereas the result remained significant, TC (95\% CI $\left.[-0.81,-0.60], I^{2}=0 \%\right)$, TG (95\% CI $\left.[-0.66,-0.38], I^{2}=72 \%\right)$, LDL-C (95\% CI $\left.[-0.77,-0.32], I^{2}=77 \%\right)$, and HDL-C (95\% CI [0.28, 0.39], $\left.I^{2}=0 \%\right)$.

\section{Discussion}

To the best of our knowledge, this systematic review of six RCTs is the latest and most comprehensive data analysis of $S$. miltiorrhiza in the treatment of PCOS so far, and it was designed to evaluate the reproductive and metabolic effects of S. miltiorrhiza in women with PCOS. Compared with the control group, S. miltiorrhiza extract may improve pregnancy rate; decrease $\mathrm{T}, \mathrm{FSH}$, fasting blood glucose, fasting insulin, TC, TG, and LDL-C; increase HDL-C. However, there is no strong evidence that $S$. miltiorrhiza extract has an effect on BMI and WHR. For patients with PCOS, excessive androgen and insulin resistance can reduce endometrial function leading to decreased fertility [35-37]. Based on current evidence, $S$. miltiorrhiza may be recommended for the treatment of PCOS patients with a desire for fertility and/ or those with hyperandrogenism and metabolic disorders.

Based on our results, oral S. miltiorrhiza extract appears to have an effect on the pregnancy rate in PCOS patients.
S. miltiorrhiza may improve fertility through various possible mechanisms. For example, when the endometrial microcirculation is disturbed, the implantation rate is low, and S. miltiorrhiza can modify endometrial microcirculation-related indicators, such as the endometrial pulsatility index and resistance index, and thus improve endometrial receptivity to provide a good environment for embryo implantation $[38,39]$. It also improves the efficacy of PMSG for increasing the pregnancy rate [40]. In addition, traditional Chinese medicine decoctions containing S. miltiorrhiza have been shown to improve reproductive outcomes by regulating the expression of proteins such as integrin, vascular endothelial growth factor, and uncoupling protein 2, which are closely related to endometrial receptivity [41]. Hyperandrogenemia is the main endocrine characteristic of PCOS. Hyperinsulinemia and IR are considered to be the main causes of hyperandrogenemia $[35,36]$, while excessive androgen leads to increased levels of LH and FSH [37]. In PCOS, theca cells and granulosa cells overexpress mRNA encoding enzymes involved in steroidogenesis, including androgen receptor, CYP11, CYP17, and CYP19, and this can lead to disturbances in ovarian hormone synthesis. The recent studies have shown that S. miltiorrhiza extract can reverse reproductive disorders by regulating the expression of androgen receptor, CYP11, CYP17, and CYP19, thus improving reproductive hormone production such as T, LH, and FSH $[15,21]$. 


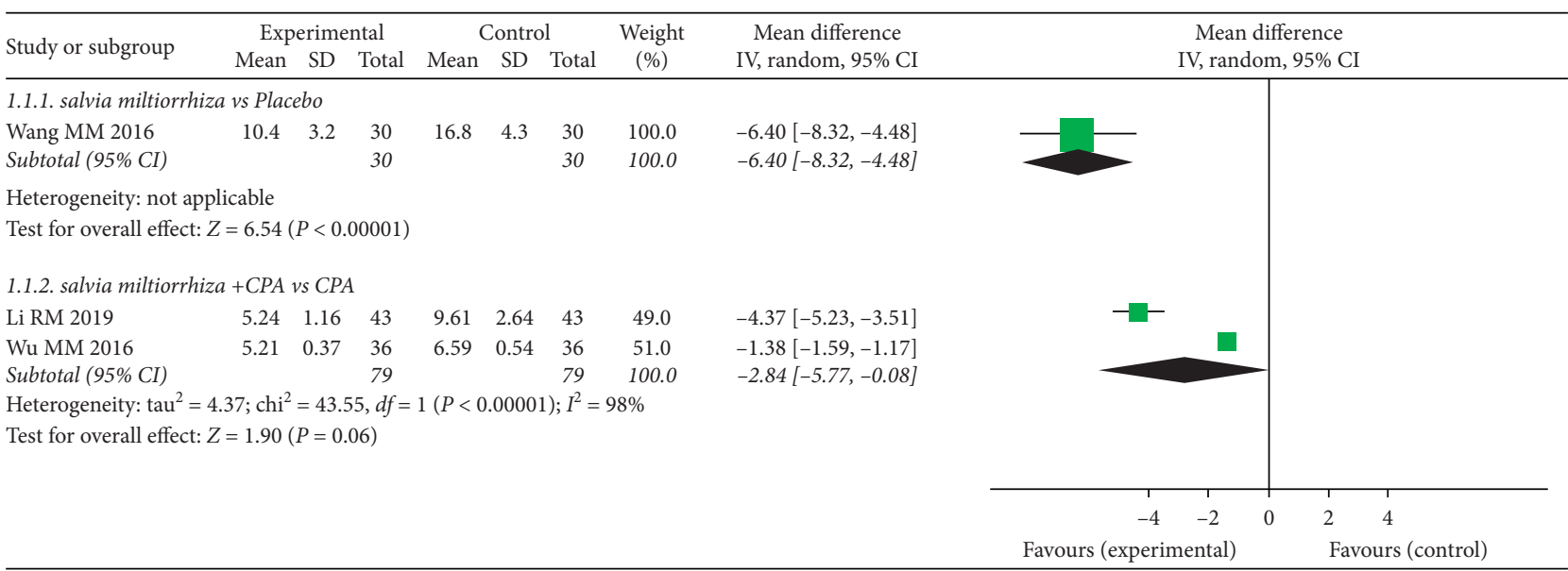

(a)

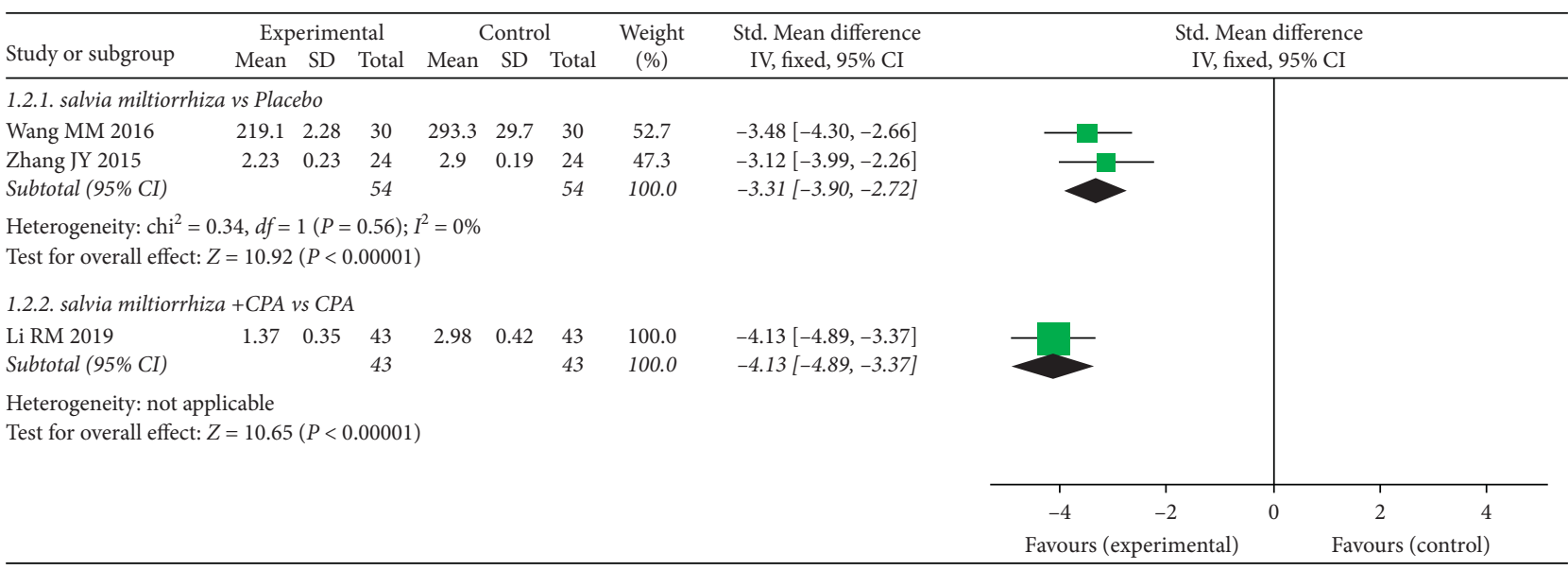

(b)

FIGURE 3: Meta-analyses of the effect of S. miltiorrhiza on reproductive hormones: (a) LH; (b) T.

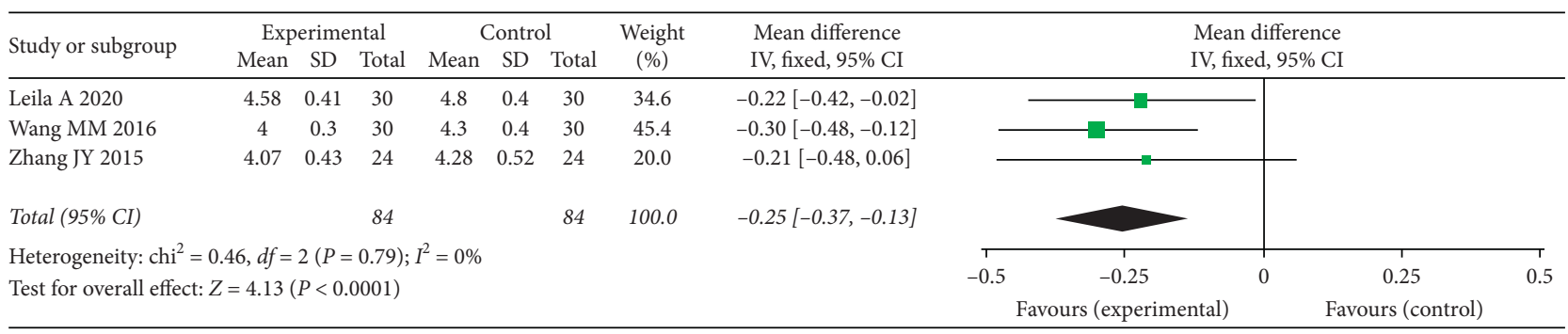

(a)

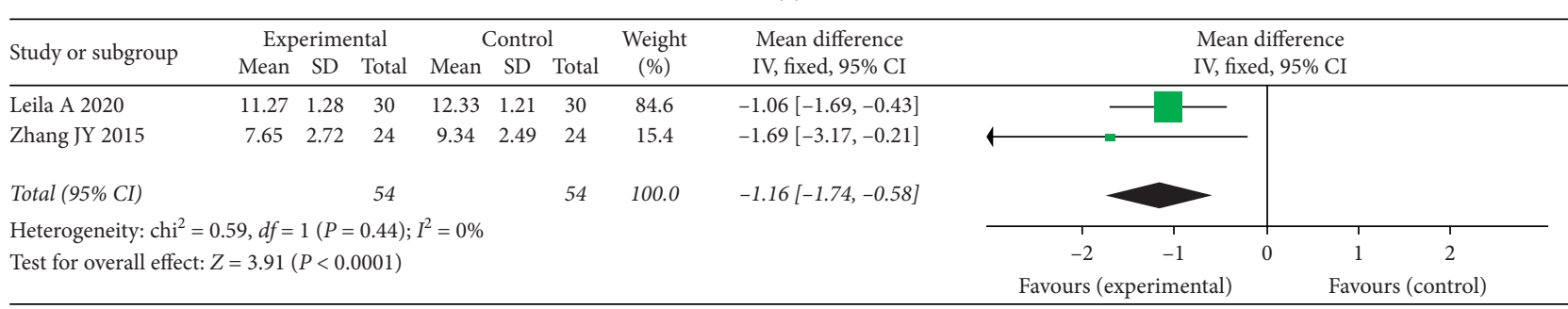

(b)

FIGURE 4: Meta-analyses of the effects of S. miltiorrhiza on glucose metabolism indexes: (a) fasting blood glucose; (b) fasting insulin. 


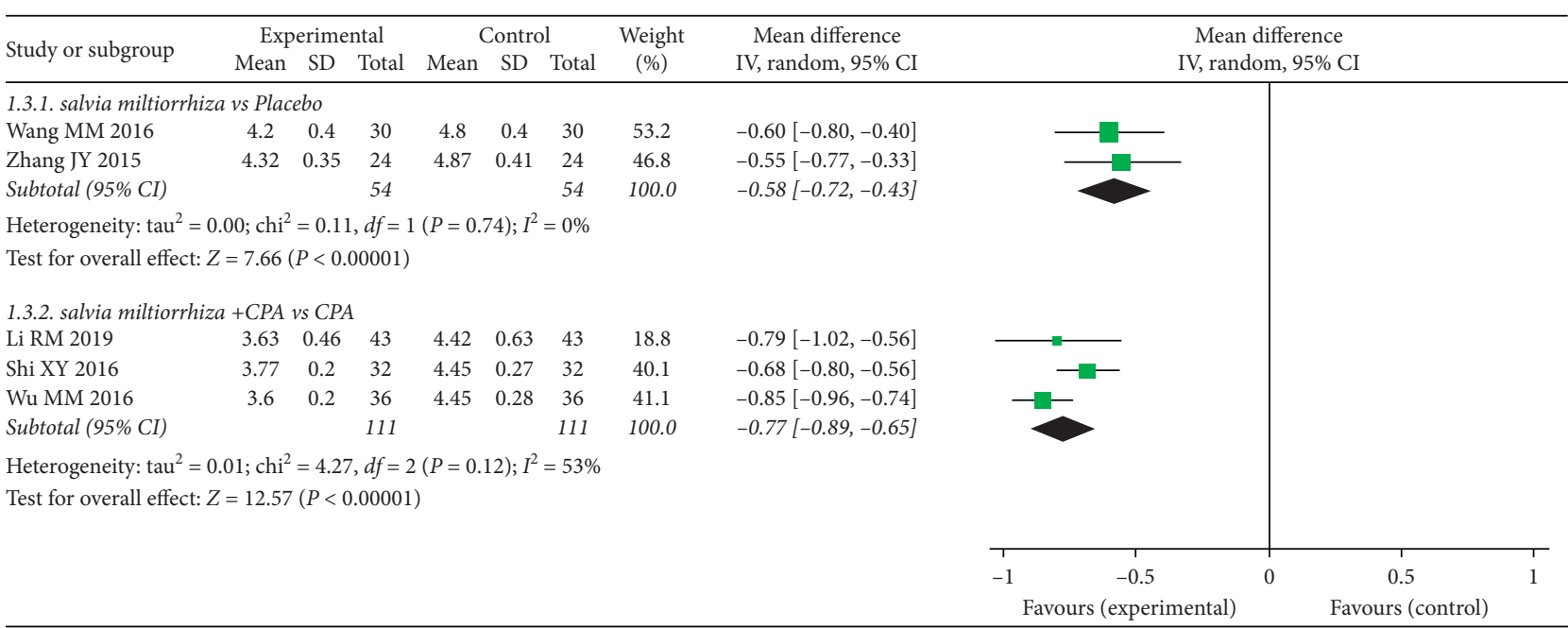

(a)

\begin{tabular}{|c|c|c|c|c|c|c|c|c|}
\hline \multirow{2}{*}{ Study or subgroup } & \multicolumn{3}{|c|}{ Experimental } & \multicolumn{3}{|c|}{ Control } & \multirow{2}{*}{$\begin{array}{c}\text { Weight } \\
(\%)\end{array}$} & \multirow{2}{*}{$\begin{array}{l}\text { Mean difference } \\
\text { IV, random, } 95 \% \text { C }\end{array}$} \\
\hline & Mean & SD & Total & Mean & SD & Total & & \\
\hline \multicolumn{9}{|c|}{ 1.4.1. salvia miltiorrhiza vs Placebo } \\
\hline Wang & 1.5 & 0.1 & 30 & 1.8 & 0.1 & 30 & 80.4 & -0.30 \\
\hline Zhang JY 20 & 1.65 & 0.16 & 24 & 1.99 & 0.2 & 24 & 19.6 & $-0.34[-0.44,-0.2$ \\
\hline Subtotal $(95 \%$ CI) & & & 54 & & & 54 & 100.0 & $-0.31[-0.35,-0.2$ \\
\hline
\end{tabular}

Heterogeneity: $\operatorname{tau}^{2}=0.00 ;$ chi $^{2}=0.47, d f=1(P=0.49) ; I^{2}=0 \%$

Test for overall effect: $Z=13.30(P<0.00001)$

1.4.2. salvia miltiorrhiza + CPA vs CPA

$\begin{array}{lll}\text { Li RM } 2019 & 0.84 & 0.25\end{array}$

$\begin{array}{llll}1.28 & 0.34 & 43 & 31.6\end{array}$

$\begin{array}{llll}1.98 & 0.16 & 32 & 34.0\end{array}$

$\begin{array}{lccccccc}\text { Wu MM } 2016 & 0.83 & 0.1 & 36 & 1.09 & 0.13 & 36 & 34.4 \\ \text { Subtotal }(95 \% \text { CI) } & & & 111 & & & 111 & 100.0\end{array}$

Subtotal (95\% CI)

$111 \quad 100.0$

Heterogeneity: $\operatorname{tau}^{2}=0.04 ; \mathrm{chi}^{2}=52.06, d f=2(P<0.00001) ; I^{2}=96 \%$

Test for overall effect: $Z=3.71(P=0.0002)$

$-0.44[-0.57,-0.31]$
$-0.58[-0.65,-0.51]$
$-0.26[-0.31,-0.21]$
$-0.43[-0.65,-0.20]$

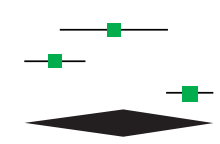

\begin{tabular}{|c|c|c|c|c|}
\hline-0.5 & -0.25 & 0 & 0.25 & 0.5 \\
\hline Favours & erimen & \multicolumn{3}{|c|}{ Favours (control) } \\
\hline
\end{tabular}

(b)

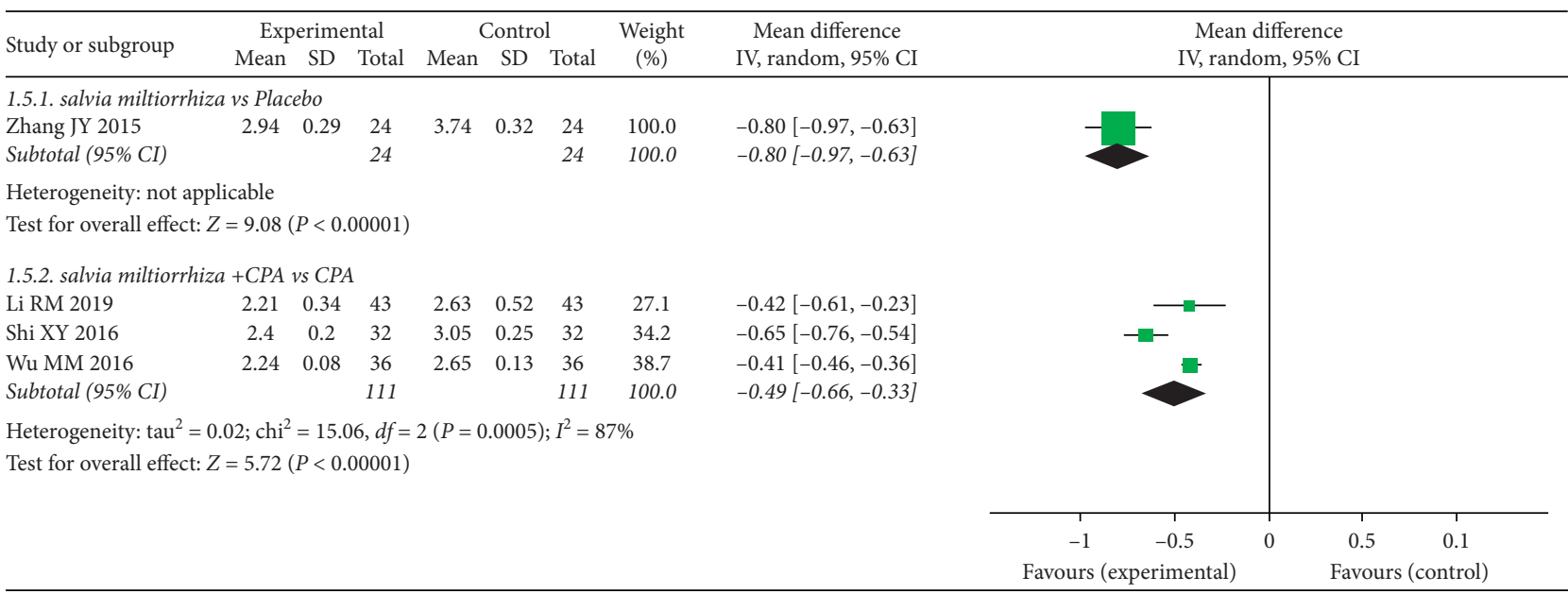

(c)

Figure 5: Continued. 


\begin{tabular}{|c|c|c|c|c|c|c|c|c|c|c|c|c|}
\hline \multirow{2}{*}{ Study or subgroup } & \multicolumn{3}{|c|}{ Experimental } & \multicolumn{3}{|c|}{ Control } & \multirow{2}{*}{$\begin{array}{c}\text { Weight } \\
(\%)\end{array}$} & \multirow{2}{*}{$\begin{array}{l}\text { Mean difference } \\
\text { IV, random, } 95 \% \mathrm{CI}\end{array}$} & \multirow{2}{*}{\multicolumn{4}{|c|}{$\begin{array}{l}\text { Mean difference } \\
\text { IV, random, } 95 \% \mathrm{CI}\end{array}$}} \\
\hline & Mean & SD & Total & Mean & SD & Total & & & & & & \\
\hline \multicolumn{13}{|c|}{ 1.6.1. salvia miltiorrhiza vs Placebo } \\
\hline Zhang JY 2015 & 0.84 & 0.1 & 24 & 0.61 & 0.07 & 24 & 100.0 & $0.23[0.18,0.28]$ & & & & \\
\hline Subtotal (95\% CI) & & & 24 & & & 24 & 100.0 & $0.23[0.18,0.28]$ & & & & \\
\hline \multicolumn{13}{|c|}{$\begin{array}{l}\text { Heterogeneity: not applicable } \\
\text { Test for overall effect: } Z=9.23(P<0.00001)\end{array}$} \\
\hline \multicolumn{13}{|c|}{ 1.6.2. salvia miltiorrhiza $+C P A$ vs $C P A$} \\
\hline Li RM 2019 & 1.64 & 0.49 & 43 & 1.23 & 0.34 & 43 & 19.6 & $0.41[0.23,0.59]$ & & & & \\
\hline Shi XY 2016 & 1.34 & 0.13 & 32 & 1.01 & 0.09 & 32 & 42.5 & $0.33[0.28,0.38]$ & & & & \\
\hline Wu MM 2016 & 1.45 & 0.19 & 36 & 1.24 & 0.14 & 36 & 37.9 & $0.21[0.13,0.29]$ & & & - - & \\
\hline Subtotal (95\% CI) & & & 111 & & & 111 & 100.0 & $0.30[0.20,0.40]$ & & & & \\
\hline \multirow{2}{*}{\multicolumn{13}{|c|}{$\begin{array}{l}\text { Heterogeneity: } \operatorname{tau}^{2}=0.01 ; \mathrm{chi}^{2}=7.83, d f=2(P=0.02) ; I^{2}=74 \% \\
\text { Test for overall effect: } Z=5.75(P<0.00001)\end{array}$}} \\
\hline & & & & & & & & & & & & \\
\hline & & & & & & & & & -0.5 & -0.25 & $\begin{array}{ll}0 & 0.25\end{array}$ & 0.5 \\
\hline & & & & & & & & & \multicolumn{4}{|c|}{ Favours (control) $\quad$ Favours (experimental) } \\
\hline
\end{tabular}

(d)

FIgUre 5: Meta-analyses of the effects of S. miltiorrhiza on lipid metabolism indexes: (a) TC; (b) TG; (c) LDL-C; and (d) HDL-C.

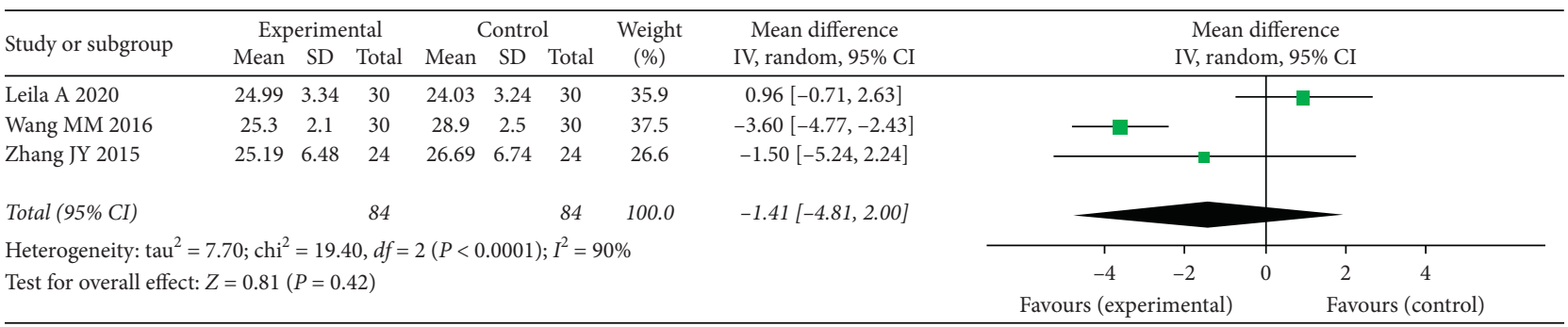

(a)

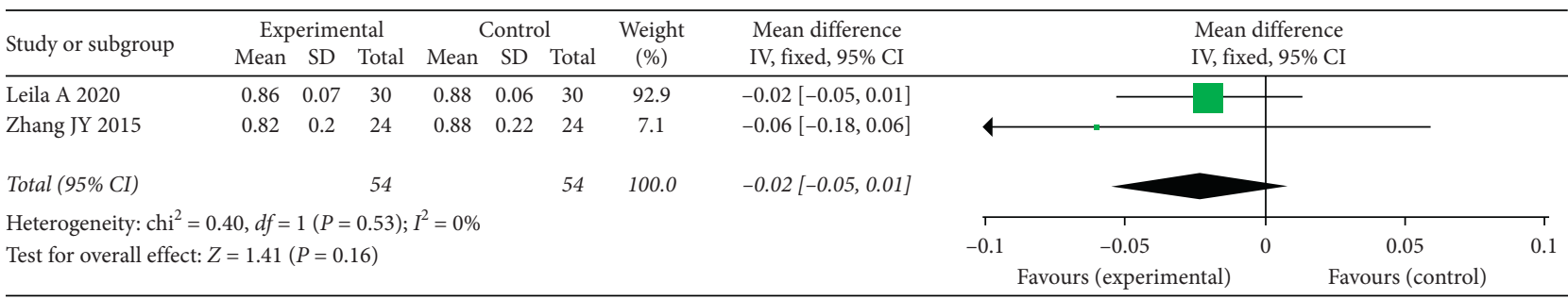

(b)

FIgURE 6: Meta-analyses of the effect of S. miltiorrhiza on (a) BMI and (b) WHR.

Another important result to take into consideration is the positive effect of $S$. miltiorrhiza extract on lipid profiles in PCOS patients. Animal and experimental studies have shown that $S$. miltiorrhiza has antiobesity effects, and in vitro studies have shown that $S$. miltiorrhiza inhibits adipogenesis in 3T3-L1 preadipocytes, with this inhibition mainly occurring at an early phase of adipogenesis through the attenuation of mitotic clonal expansion via cell cycle arrest at the G1/S phase transition [42]. It also can suppress adipogenesis and reduce obesity-related metabolic disorders by acting on PPAR $\gamma, \mathrm{C} / \mathrm{EBP} \alpha, \mathrm{GATA}-2$, and GATA-3 [43]. Tanshinone IIA also suppresses fatty acid-induced lipogenesis and TG accumulation in HepG2 cells [44], and a recent study has shown that $S$. miltiorrhiza significantly decreases TC, TG, and LDL-C levels in mice by inhibiting the expression of FAS mRNA and HMGR mRNA [45].
Furthermore, S. miltiorrhiza extract reduces the upregulation of SREBP1 and TG induced by high glucose in LO2 cells, which improves lipid metabolism, and the underlying mechanism is probably through the regulation of STAT-3 signaling [46]. Lastly, S. miltiorrhiza can activate the estrogen receptor through the ERK signaling pathway, reducing lipid deposition in the aorta [16].

Beyond its effects on lipid profiles, S. miltiorrhiza has positive effects on other aspects of PCOS patients' health. PCOS is closely related to metabolic syndrome $[47,48]$, and several studies have demonstrated the different effects of S. miltiorrhiza on hypoglycemia and hypoinsulinemia. Adiponectin (APN) and leptin are closely related to obesity [49]. The imbalance of adipose cytokines such as leptin and adiponectin secreted by adipose tissue in obese patients also aggravates the IR associated with PCOS [50]. S. miltiorrhiza 
extract increases the sensitivity to insulin by inducing the production and secretion of anti-inflammatory adipokines (such as APN), and it reduces inflammation and the production of proinflammatory cytokines $[51,52]$. Tanshinone I may also decrease fasting blood glucose concentrations by decreasing levels of interleukin- 6 and tumor necrosis factoralpha and by reducing the nuclear translocation of NF- $\kappa \mathrm{B}$ and the phosphorylation of Ser307 on insulin receptor substrate 1 (IRS-1) [42]. It is also suggested that the hypoglycemic effect of $S$. miltiorrhiza extract is likely to be secondary to an action on carbohydrate metabolism [53]. The observed decrease in fasting blood glucose and fasting insulin concentrations may be a result of cryptotanshinone rescuing the altered protein expressions of IRS-1 and IRS-2, phosphatidylinositol 3-kinase p85 $\alpha$, glucose transporter-4, ERK-1, and 17 $\alpha$-hydroxylase [54]. Lastly, cryptotanshinone stimulates insulin signaling and the regulation of glucose transporters and hormone-synthesizing enzymes, which reverses ovarian IR in mice [21].

There is no strong evidence in our analysis that S. miltiorrhiza extract has effects on BMI and WHR. The only exception was the study by Wang et al. [23], who found that the $S$. miltiorrhiza extract group significantly reduced BMI compared with placebo.

Among the included studies, Zhang et al. [33] reported that no adverse reactions occurred during the treatment, such as gastrointestinal discomfort, skin rashes, dizziness and headaches, blood system changes, and liver and kidney damage, while the other studies did not mention anything about adverse events at all. In addition, a more recent study [55] has shown that S. miltiorrhiza has the advantages of strong activity, low toxicity, low side effects, and extensive pharmacological effects. Therefore, we believe that S. miltiorrhiza is a relatively safe treatment, although more clinical studies are needed to confirm the safety of S. miltiorrhiza in long-term treatment.

This review included six recent RCTs (2015-2020), and limitations include the small number of studies, the small sample sizes, the lack of blinding in most of the studies, missing descriptions of the randomization method in some studies, and results with high heterogeneity (e.g., TC, TG, LDL-C, and HDL-C). Bias risk sensitivity analysis was used to investigate the high heterogeneity. After the study by $\mathrm{Wu}$ et al. was excluded, TC and HDL-C showed homogeneity. The heterogeneity might therefore be related to the place where the experiment took place, the subjects' dietary habits, and their own constitutions. The interventions included in this study included $S$. miltiorrhiza extract combined with CPA or LET. CPA was used as a combination oral contraceptive and LET was used as an ovulation-induction drug. The mechanism of action and the goal in clinical application of the two are different, so the data from these studies were not combined. The study time was generally short to medium term (mostly 3 months), and there was a lack of followup observation of the long-term efficacy of S. miltiorrhiza. In addition, the adverse effects of $S$. miltiorrhiza on PCOS are unknown because most trials did not report adverse events, and caution should be used in interpreting the safety of S. miltiorrhiza. Finally, we still need a large sample, multiple center, and scientifically validated RCTs to further verify the efficacy of S. miltiorrhiza in the treatment of PCOS and to provide solid and reliable evidence for clinical practice.

\section{Conclusion}

In summary, the results of the present systematic review and meta-analysis indicate that $S$. miltiorrhiza has beneficial effects on reproduction and glucose and lipid metabolism in patients with PCOS. Moreover, our results demonstrate that the clinical application of S. miltiorrhiza is generally safe. However, due to the relatively low quality of the included studies, we urge caution in promoting these results. More prospective RCTs with large samples, multiple centers, and longer intervention durations are warranted in the future to obtain more scientific, objective, and reliable conclusions.

\section{Data Availability}

The data used to support the findings of this study are available from the corresponding author upon request.

\section{Disclosure}

Wenjuan Shen, Bao Jin, and Yaguang Han are co-first authors.

\section{Conflicts of Interest}

The authors declare that they have no conflicts of interest.

\section{Acknowledgments}

This work was supported by the Young Scientists Fund of the National Natural Science Foundation of China (81803945), the Scientific Research Project of Traditional Chinese Medicine in Heilongjiang Province (ZHY19024), and the Excellent Innovative Talents Project of the Education Bureau of Heilongjiang Province (UNPYSCT-2018224).

\section{References}

[1] R. Azziz, E. Carmina, Z. Chen et al., "Polycystic ovary syndrome," Nature Reviews Disease Primers, vol. 2, no. 1, p. 16057, 2016.

[2] D. Lizneva, L. Suturina, W. Walker, S. Brakta, L. GavrilovaJordan, and R. Azziz, "Criteria, prevalence, and phenotypes of polycystic ovary syndrome," Fertility and Sterility, vol. 106, no. 1 , pp. $6-15,2016$.

[3] R. Azziz, E. Carmina, D. Dewailly et al., "The androgen excess and PCOS society criteria for the polycystic ovary syndrome: the complete task force report," Fertility and Sterility, vol. 91, no. 2, pp. 456-488, 2009.

[4] L. J. Moran, R. J. Norman, and H. J. Teede, "Metabolic risk in PCOS: phenotype and adiposity impact," Trends in Endocrinology \& Metabolism, vol. 26, no. 3, pp. 136-143, 2015.

[5] D. Caserta, G. Adducchio, S. Picchia, E. Ralli, E. Matteucci, and M. Moscarini, "Metabolic syndrome and polycystic ovary syndrome: an intriguing overlapping," Gynecological Endocrinology, vol. 30, no. 6, pp. 397-402, 2014.

[6] B. C. J. M. Fauser, B. C. Tarlatzis, R. W. Rebar et al., "Consensus on women's health aspects of polycystic ovary 
syndrome (PCOS): the Amsterdam ESHRE/ASRM-Sponsored 3rd PCOS consensus workshop group," Fertility and Sterility, vol. 97, no. 1, pp. 28-38, 2012.

[7] T. Ding, P. J. Hardiman, I. Petersen, and G. Baio, "Incidence and prevalence of diabetes and cost of illness analysis of polycystic ovary syndrome: a Bayesian modelling study," Human Reproduction, vol. 33, no. 7, pp. 1299-1306, 2018.

[8] N. Naderpoor, S. Shorakae, A. Joham, J Boyle, B De Courten, and H. J Teede, "Obesity and polycystic ovary syndrome," Minerva Endocrinologica, vol. 40, no. 1, pp. 37-51, 2015.

[9] S. Arentz, C. A. Smith, J. Abbott, and A. Bensoussan, "Nutritional supplements and herbal medicines for women with polycystic ovary syndrome; a systematic review and metaanalysis," BMC Complementary and Alternative Medicine, vol. 17 , no. 1, p. 500, 2017.

[10] H. Lan, Z. H. Zhu, F. F. Lv et al., "Research progress on prevention and treatment of polycystic ovary syndrome by Chinese herbal medicine of homology of medicine and food," Liaoning Journal of Traditional Chinese Medicine, vol. 47, no. 10, pp. 209-212, 2020.

[11] Y. Zhang, H. P. Mao, and G. W. Fan, "Recent advances in study of Dan shen (salvia miltiorrhiza)," Journal of Tianjin University of Traditional Chinese Medicine, vol. 38, no. 1, pp. 15-19, 2019.

[12] M. L. Li, Z. X. Zhang, T. L. Du, Q. M. Xia, and H. Zhang, "The application of salviae miltiorrhizae bunge in dermatology," Chinese Journal of Aesthetic Medicine, vol. 24, no. 14, pp. 79-82, 2015.

[13] L.-N. Li, "Biologically active components from traditional Chinese medicines," Pure and Applied Chemistry, vol. 70, no. 3, pp. 547-554, 1998.

[14] M.-H. Li, Y. Peng, and P.-G. Xiao, "Distribution of tanshinones in the genusSalvia(family Lamiaceae) from China and its systematic significance," Journal of Systematics and Evolution, vol. 48, no. 2, pp. 118-122, 2010.

[15] J. Yu, D. X. Zhai, L. Hao et al., "Cryptotanshinone reverses reproductive and metabolic disturbances in PCOS model rats via regulating the expression of CYP17 and AR," EvidenceBased Complementary and Alternative Medicine, vol. 2014, Article ID 670743, 10 pages, 2014.

[16] X. Liu, C.-Y. Guo, X.-J. Ma et al., "Anti-inflammatory effects of tanshinone IIA on atherosclerostic vessels of ovariectomized ApoE-/- mice are mediated by estrogen receptor activation and through the ERK signaling pathway," Cellular Physiology and Biochemistry, vol. 35, no. 5, pp. 1744-1755, 2015.

[17] J. Wen, Y. Chang, S. Huo et al., "Tanshinone IIA attenuates atherosclerosis via inhibiting NLRP3 inflammasome activation," Aging, vol. 13, no. 1, pp. 910-932, 2020.

[18] Y. Dong, S. L. Morris-Natschke, and K.-H. Lee, "Biosynthesis, total syntheses, and antitumor activity of tanshinones and their analogs as potential therapeutic agents," Natural Product Reports, vol. 28, no. 3, pp. 529-542, 2011.

[19] Q. Hu, B. Wei, L. Wei et al., "Sodium tanshinone IIA sulfonate ameliorates ischemia-induced myocardial inflammation and lipid accumulation in Beagle dogs through NLRP3 inflammasome," International Journal of Cardiology, vol. 196, pp. 183-192, 2015.

[20] L. D. C. Mannelli, M. Piccolo, F. Maione et al., "Tanshinones from Salvia miltiorrhiza Bunge revert chemotherapy-induced neuropathic pain and reduce glioblastoma cells malignancy," Biomedicine \& Pharmacotherapy = Biomedecine \& Pharmacotherapie, vol. 105, pp. 1042-1049, 2018.
[21] Y. Huang, W. Li, C. C. Wang, X. Wu, and J. Zheng, "Cryptotanshinone reverses ovarian insulin resistance in mice through activation of insulin signaling and the regulation of glucose transporters and hormone synthesizing enzymes," Fertility and Sterility, vol. 102, no. 2, pp. 589-596, 2014.

[22] Y. J. Yang, L. Yang, C. Qi et al., "Cryptotanshinone alleviates polycystic ovary syndrome in rats by regulating the HMGB1/ TLR4/NF- $\kappa \mathrm{B}$ signaling pathway," Molecular Medicine Reports, vol. 22, no. 5, pp. 3851-3861, 2020.

[23] M. M. Wang, H. Y. Xue, and J. X. Zhong, "Effect of tanshinone pretreatment combined with ovulation induction therapy on pregnancy outcome in patients with polycystic ovary syndrome complicated with metabolic disorders," Chinese Journal of Clinical Research, vol. 29, no. 11, pp. 1479-1481, 2016.

[24] N. M. Wang, Y. F. Yang, H. X. Wang, and C. Y. Yang, "Clinical research of menshi xiaonang yin combined with tanshinone capsules in the treatment of kidney deficiency and phlegm stasis type polycystic ovary syndrome," Lishizhen Medicine and Materia Medica Research, vol. 29, no. 9, pp. 2200-2203, 2018.

[25] J. Su, H. Y. Xue, X. Q. Fan, and Y. Q. Cheng, "Effect of tanshinone on glucose metabolism in patients with polycystic ovary syndrome," Medical Journal of National Defending Forces in Northwest China, vol. 36, no. 9, pp. 610-612, 2015.

[26] A. Liberati, D. G. Altman, J. Tetzlaff et al., "The PRISMA statement for reporting systematic reviews and meta-analyses of studies that evaluate healthcare interventions: explanation and elaboration," BMJ, vol. 339, no. 1, p. b2700, 2009.

[27] Endocrinology Division and Chinese Society of Obstetrics and Gynecology, "Expert consensus on the diagnosis and treatment of polycystic ovary syndrome," Chinese Journal of Obstetrics and Gynecology, vol. 43, no. 7, pp. 553-555, 2008.

[28] R. Azziz, E. Carmina, D. Dewailly et al., "Criteria for defining polycystic ovary syndrome as a predominantly hyperandrogenic syndrome: an androgen excess society guideline," The Journal of Clinical Endocrinology \& Metabolism, vol. 91, no. 11, pp. 4237-4245, 2006.

[29] J. E. Higgins and S. Green, "Cochrane handbook for systematic reviews of interventions [EB/O]," 2011, http:// handbook.cochrane.org/.

[30] M. M. Wu, N. Liu, and L. Han, "Effect of tanshinone capsule on lipid metabolism and hypothalamic-pituitary-adrenal axis in patients with polycystic ovary syndrome," Shandong Medical Journal, vol. 56, no. 32, pp. 94-96, 2016.

[31] R. M. Li, "Clinical observation of tanshinone capsule combined with ethinylestradiol cyproterone in the treatment of 43 patients with polycystic ovary syndrome at childbearing age," Ningxia Medical Journal, vol. 41, no. 2, pp. 172-173, 2019.

[32] L. Amini, F. Mojab, S. Jahanfar, M. Sepidarkish, Z. Raoofi, and A. Maleki-Hajiagha, "Efficacy of Salvia officinalis extract on the prevention of insulin resistance in euglycemic patients with polycystic ovary syndrome: a double-blinded placebocontrolled clinical trial," Complementary Therapies in Medicine, vol. 48, Article ID 102245, 2020.

[33] J. Y. Zhang, H. Y. Xue, J. Su et al., "Clinical effects of tanshinone on polycystic ovary syndrome patients with hyperandrogenism," Guangxi Medical Journal, vol. 37, no. 6, pp. 767-769, 2015.

[34] X. Y. Shi, Y. Q. Wang, and Q. Li, "Study on the therapeutic effect of integrated traditional Chinese and western medicine on patients with polycystic ovary syndrome and its influence on lipid metabolism," Journal of Frontiers of Medicine, vol. 6, no. 29, pp. 181-182, 2016. 
[35] Y. L. Li, X. Y. Ruan, and A. O. Mueck, "Effect of polycystic ovary syndrome on pregnancy outcomes," Journal of Capital Medical University, vol. 37, no. 4, pp. 449-453, 2016.

[36] W. Ye, T. Xie, Y. Song, and L. Zhou, "The role of androgen and its related signals in PCOS," Journal of Cellular and Molecular Medicine, vol. 25, no. 4, pp. 1825-1837, 2021.

[37] P. Moghetti and F. Tosi, "Insulin resistance and PCOS: chicken or egg?" Journal of Endocrinological Investigation, vol. 44, no. 2, pp. 233-244, 2021.

[38] Q. Zeng, H. X. Zhang, and Y. N. Wang, "Effect of bushen huatan huoxue method on endometrial tolerance in patients with PCOS ovulation infertility," Journal of Sichuan of Traditional Chinese Medicine, vol. 35, no. 8, pp. 136-139, 2017.

[39] B. Y. Lv, D. Li, H. L. Zhang, and X. Y. Xin, "Effect and regulation mechanism of Chinese Bushen Huoxue prescriptions on endometrial receptivity," China Journal of Chinese Materia Medica, vol. 43, no. 10, pp. 2014-2019, 2018.

[40] W. Li, C. H. Zhou, Q. L. Lu, and Y. C. Yu, "Effect and Mechanism of Chinese Huoxue Tongjing prescriptions on on ovarian and uterine function," Chinese Journal of Integrated Traditional and Western Medicine, vol. 12, no. 3, pp. 165-168+134, 1992.

[41] Q. Ding, J. Y. Li, J. Xu et al., "Effects of danshen injection on $\alpha v \beta 3$,PDGF and TIMP- 1 in endometrium of patients with moderate to severe intrauterine adhesions," Journal of Hunan University of Chinese Medicine, vol. 32, no. 10, pp. 52-54, 2012.

[42] D. Y. Jung, J.-H. Kim, and M. H. Jung, "Anti-obesity effects of tanshinone I from salvia miltiorrhiza bunge in mice fed a high-fat diet through inhibition of early adipogenesis," $\mathrm{Nu}$ trients, vol. 12, no. 5, p. 1242, 2020.

[43] P. Wng, S. Xu, W. Li et al., "Salvianolic acid B inhibited PPAR $\gamma$ expression and attenuated weight gaina in mice with high-fat diet-induced obesity," Cellular Physiology and Biochemistry: International Journal of Experimental Cellular Physiology, Biochemistry, and Pharmacology, vol. 34, no. 2, pp. 288-298, 2014.

[44] W.-Y. Gao, P.-Y. Chen, H.-J. Hsu, C.-Y. Lin, M.-J. Wu, and J.-H. Yen, "Tanshinone IIA downregulates lipogenic gene expression and attenuates lipid accumulation through the modulation of LXR $\alpha$ /SREBP1 pathway in HepG2 cells," Biomedicines, vol. 9, no. 3, p. 326, 2021.

[45] J. Chen, J. Deng, Y. Y. Deng et al., "Study on regulatory effect of Danshensu on lipid metabolism of hyperlipidemia rats," China Journal of Chinese Materia Medica, vol. 40, no. 2, pp. 313-317, 2015.

[46] J. Chen, J. Yue, J. Liu et al., "Salvianolic acids improve liver lipid metabolism in ovariectomized rats via blocking STAT-3/ SREBP1 signaling," Chinese Journal of Natural Medicines, vol. 16 , no. 11 , pp. 838-845, 2018.

[47] A. Aflatounian, M. C. Edwards, V. Rodriguez Paris et al., "Androgen signaling pathways driving reproductive and metabolic phenotypes in a PCOS mouse model," Journal of Endocrinology, vol. 245, no. 3, pp. 381-395, 2020.

[48] K. S. Olaniyi, A. A. Oniyide, O. A. Adeyanju, L. S. Ojulari, A. O. Omoaghe, and O. E. Olaiya, "Low dose spironolactonemediated androgen-adiponectin modulation alleviates endocrine-metabolic disturbances in letrozole-induced PCOS," Toxicology and Applied Pharmacology, vol. 411, Article ID 115381, 2021.

[49] Y. Tang, D. Wang, H. Zhang et al., "Rapid responses of adipocytes to iron overload increase serum TG level by decreasing adiponectin," Journal of Cellular Physiology, 2021.
[50] S. F. M. Medeiros, R. J. Rodgers, and R. J. Norman, “Adipocyte and steroidogenic cell cross-talk in polycystic ovary syndrome," Human Reproduction Update, 2021.

[51] N. Rahman, M. Jeon, H.-Y. Song, and Y.-S. Kim, "Cryptotanshinone, a compound of Salvia miltiorrhiza inhibits preadipocytes differentiation by regulation of adipogenesis-related genes expression via STAT3 signaling," Phytomedicine, vol. 23, no. 1, pp. 58-67, 2016.

[52] F. Y. Yuan, M. Zhang, P. Xu et al., "Tanshinone IIA improves diabetes mellitus via the NF- $\kappa \mathrm{B}$-induced AMPK signal pathway," Experimental and Therapeutic Medicine, vol. 16, no. 5, pp. 4225-4231, 2018.

[53] M. A. Carai, G. Colombo, B. Loi et al., "Hypoglycemic effects of a standardized extract of salvia miltiorrhiza roots in rats," Pharmacognosy Magazine, vol. 11, no. 11, pp. S545-S549, 2015.

[54] X. Yang, Y. Zhang, X. Wu et al., "Cryptotanshinone reverses reproductive and metabolic disturbances in prenatally androgenized rats via regulation of ovarian signaling mechanisms and androgen synthesis," American Journal of Physiology. Regulatory, Integrative and Comparative Physiology, vol. 300, no. 4, pp. 869-875, 2011.

[55] T. Y. Lou, B. B. Ma, Y. Y. Liang et al., "Analysis and identification of metabolites of cryptotanshinone in rats by UHPLC-Q-exactive mass spectrometer," Journal of Chinese Mass Spectrometry Society, vol. 41, no. 4, pp. 307-320, 2020. 